\title{
Digitalization of Human Head Anthropometry Measurement Using Pixels Measurement Method
}

\author{
Fandy Surya Pratama ${ }^{1}$, Istianah Muslim², Muhammad Ihsan Zul ${ }^{3}$
}

\begin{abstract}
Head Anthropometry is a part of anthropometry that needed to be measured carefully. It is because human head becomes an important part that necessary to be protected. The protection aims to look after the safety of the human head. Safety factors can be achieved by designing head products. Therefore, head anthropometry data is required to make a product design Currently, data retrieval of head anthropometry is still using several measuring devices such as anthropometers, sliding callipers, spreading callipers, and tape gauges. This measurement method makes the standard deviation become higher and also take a lot of time to capture huge amounts of anthropometry data. However, the problem has been resolved by other study research with building a head dimension measurement system using digital camera. But the system still need the integration with digital camera. This study uses the IP Camera that has been integrated with the system to capture human head from the front and side. The captured image is segmented into several areas based on head dimension. Then, the image is processed using pixel measurement method by performing feature extraction on each head dimension to get the result of head dimension measurement. The result shows that calliper measurement and system measurement against ten of fourteen human head anthropometry dimensions is identical with the best distance between IP Camera and the head as far as $200 \mathrm{~cm}$. This head anthropometry data is expected to make a contribution to Indonesian Ergonomics Society.
\end{abstract}

Keywords - Head Anthropometry Dimension, IP Camera, Image Segmentation, Head Feature Extraction.

\section{INTRODUCTION}

The human head is one of the important parts of the human body. There are many vital organs on the head that need to be protected. The protection aims to maintain the organs' safety and security. Safety and security factors can be achieved by designing various products that can protect these organs. In addition to the above factors, comfort factors also need to be considered so that the produced products are in accordance with human needs. To meet these three factors, a science in product design is required. The intended science is Anthropometry, science that serves to measure the dimension of human body, including the head [1]. These measurements aim to obtain data that could be used in designing products suitable for users' characteristics [2], [3]. Human head

\footnotetext{
1,3 Informatics Engineering Study Program, Caltex Riau Polytechnic, Umban Sati (Patin) St. No.1 Rumbai Pekanbaru - Riau 28265 (phone: 0761-53939; fax: 0761-554224; e-mail: fandy14ti@mahasiswa.pcr.ac.id,ihsan@pcr.ac.id)

${ }^{2}$ Information System Study Program, Caltex Riau Polytechnic, Umban Sati (Patin) St. No.1 Rumbai Pekanbaru - Riau 28265 (phone: 0761-53939; fax: 0761-554224; e-mail: istianah@pcr.ac.id)
}

dimensional measurements or head anthropometry have variables that have been set by the National Institute for Occupational Safety and Health (NIOSH) and there is also a definite measurement method [4]. Anthropometry data retrieval is often conducted with measuring instruments such as anthropometer, tape measure, sliding calliper, and spreading calliper [5]. Measurements done with those measuring instruments have resulted a high deviation standard [6]. In addition, measurements using manual measuring instruments also take a long time to obtain anthropometry data in large quantities [5].

The current rapid technology development has made the anthropometry data retrieval process can be performed more quickly and accurately. One of the utilized technologies is the implementation of digital image processing. A study uses facial image in designing attendance system with Eigen face algorithm and PCA method [7]. This system can recognize the face that was captured with a variety of expressions, head accessories, distance, and various backgrounds. The accuracy output of conducted system resulted in a sensitivity level of $73.33 \%$, a specificity level of $52.17 \%$, an accuracy rate of $70 \%$, and a face recognition accuracy of $86.67 \%$. Tests were also conducted on face images with additional accessories, such as glasses and veils of $85 \%$ and facial images with normal expressions, smiles, sadness, surprised, and blinking of $85.33 \%$.

Digital image processing technology can be applied to hardware, i.e. IP Camera [8]. This IP Camera implementation has been applied to other studies. A study utilizes the use of IP cameras to recognize the hand shape of images captured with three feature extraction methods [9]. These are Edge Detection, Vector Analysis, and Pixel to Pixel Distance Analysis. The best implemented method to identify the shape of the hand is Pixel to Pixel Distance Analysis. This method successfully recognizes the shape of the hand using the IP Camera with an accuracy of $88.33 \%$.

Other studies predict age based on face images from the KinFaceW dataset [10]. The predicted age groups are children, adolescence, and oldster. The grouping is based on Face Anthropometry, Wrinkle Density, and The Depth of Wrinkle. Facial wrinkles are identified using a combination of two feature extractions, i.e. Sobel Operator and Histogram Equalization. Age grouping is done by administering the Neural Network classification algorithm.

The previous research conducted a head dimension measurement based on anthropometry theory and the captured human head images [5]. However, the conducted research used a Canon EOS 450D camera in the process of taking the head images, so that captured images needed to be moved to a computer hard drive to be processed. In addition, the image 
processing method applied in the study required two stages of colour space conversion, i.e. the conversion of RGB space to grayscale and grayscale conversion to binary. Therefore, this paper identifies the anthropometric dimensions of human heads from images in grayscale colour space using an IP Camera that has been integrated with the system for the head image taking process. The captured head images are automatically stored in the computer. This paper also performs feature extraction to detect the dimension of head measurement. The measured head dimensions are of the front and side heads. The captured image is converted to grayscale. The images that have been converted to grayscale are subject to feature extraction process to produce front head anthropometric measurement data. The results of this study can contribute to the Indonesian Ergonomics Association (PEI) in the form of accurate anthropometric measurement data.

\section{MEthodOLOGY}

\section{A. Dimensions of Human Head Anthropometry}

The dimensions of human head measurement consist of fourteen dimensions [5]. The front head measurement has six dimensions, while the side head measurement has eight dimensions. Illustration of head dimension of the measured head anthropometry is shown in Fig. 1. A description of the position and information about each head dimension are presented in Table I.

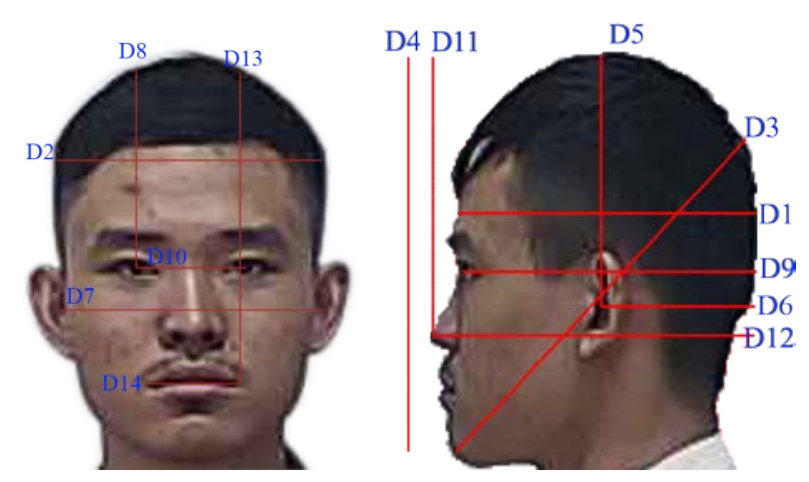

Fig. 1 Dimension of front and side head measurements [5].

\section{B. Image Processing Stages}

This research was carried out by taking the image of a human head using an IP camera. The head images were taken from front and side views. The obtained head images were then converted into grayscale images. Feature extraction was administered to the head image that had become grayscale to look for areas around the head required to identify fourteen dimensions of head anthropometric measurements. The results of anthropometric dimension measurements obtained from head grayscale images were in pixels. The value of measurement dimension was then converted into centimetre unit obtained from the division between the height dimensions of the head and the calliper s' measurement with the dimension measurement system of head height in pixel. The stages of the research process described earlier are shown in Fig. 2.
TABLE I

DESCRIPTION OF HEAD MEASUREMENT DIMENSIONS

\begin{tabular}{|c|c|l|}
\hline Dimensions & Head Position & \multicolumn{1}{|c|}{ Description } \\
\hline D1 & Side & Head length \\
\hline D2 & Front & Head width \\
\hline D3 & Side & Maximum diameter of chin \\
\hline D4 & Side & Chin to the top of the head \\
\hline D5 & Side & Ear to the top of the head \\
\hline D6 & Side & Ear to the back of the head \\
\hline D7 & Front & Between two ears \\
\hline D8 & Front & Eye to top of the head \\
\hline D9 & Side & Eye to the back of the head \\
\hline D10 & Front & Between two pupils of the eyes \\
\hline D11 & Side & Nose to the top of the head \\
\hline D12 & Side & Nose to the back of the head \\
\hline D13 & Front & Mouth to the top of the head \\
\hline D14 & Front & Mouth width \\
\hline
\end{tabular}

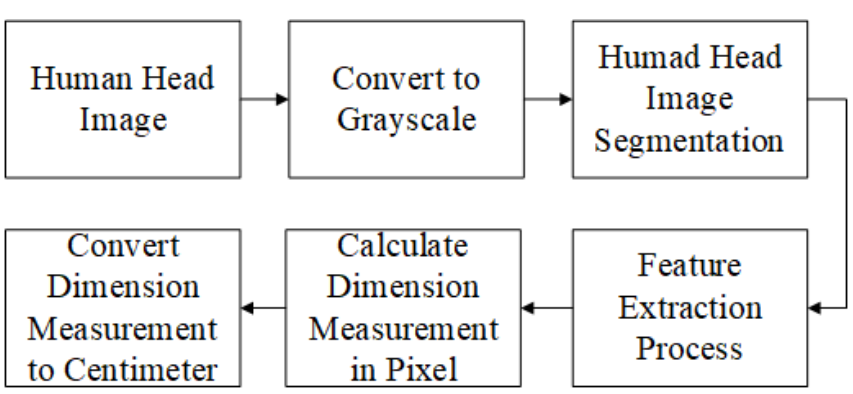

Fig. 2 Research block diagram.

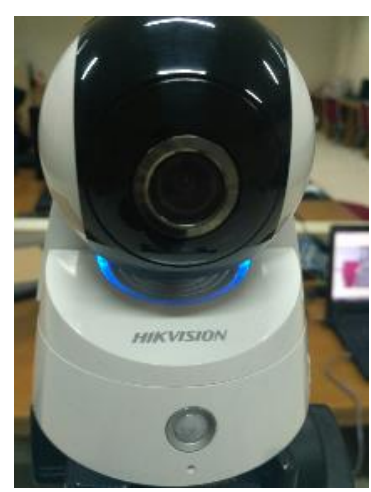

Fig. 3 HIKVision IP Camera.

\section{Setting of Image Capturing Conditions}

The human head image taking process was conducted in a room equipped with an IP camera, tripod, background, and chair. Human head images captured by the IP Camera with the HIKVision type as in Fig. 3. The use of IP Camera aimed to enable a connection to a web browser so that the captured image of a human head can be directly processed. The IP Camera was placed on a tripod functioning as a support. The size of captured human head image was $160 \times 180$ pixels. The distance of the camera's position to the head object was determined by adjusting the capturing area of overall head image, so the distance between head object and the IP camera was set at $206 \mathrm{~cm}$. The used background colour was white to ease the feature extraction process on the grayscale images. 
Adequate lighting was also important when taking head images shots in a room. The required light intensity to obtain a good captured image was in the range of 140 to 150 lux. A tool called luxe meter was used to measure the light intensity.

\section{Conversion of RGB Images to Grayscale}

The captured human head image was in an RGB colour image. The image needs to be converted into grayscale image consisting of greyish colour [11]. Each pixel in a grayscale image consists of one value with the same RGB colour value. This conversion was made to ease the process of human head dimension detection. The process of image change into grayscale can be done by (1).

$$
g^{\prime}(x, y)=\frac{g_{R}(x, y)+g_{G}(x, y)+g_{B}(x, y)}{3}
$$

with $g^{\prime}(x, y)$ are the grayscale image from the equation and $g_{R}, g_{G}, g_{B}$ are the components of RGM images captured from IP Camera.

\section{E. Image Segmentation}

The image segmentation stage then administered on the obtained human head images by dividing the head into several areas according to the needs of head dimensions [11]. Front head image was divided to determine the area of the eyes, nose, ears and mouth [5]. The front head image was split horizontally. The eye area was located at the top of the face, while the lower part of the face was divided into three parts to get the nose, ears, and mouth area.

The side head image was divided to get the ear area. First, the image was horizontally divided into two parts. The lower part of the division result was horizontally divided into two to obtain ear area from the horizontal side. After the ear area was obtained, horizontally, side head image was vertically divided into two. The midline that divided side head image into two parts then shifted to the left as much as one third of the half part of side head image. The obtained areas from segmentation stages as in Fig. 4 became a reference for feature extraction of human head dimension.
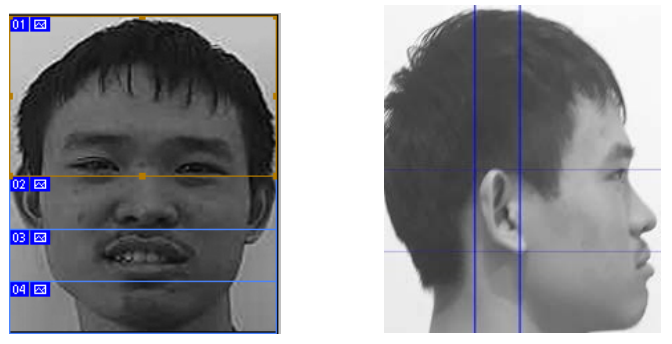

Fig. 4 Head image segmentation.

\section{F. Feature Extraction}

The feature extraction process was administered after conducting the image segmentation stage. This process was administered by identifying head dimension points that can be found by looking at the colour intensity of a darker pixel.

Each identified dimension used various area division. On the front head, head width dimension (D2) was determined by identifying each tip of the head located in between the eyebrows and hairline. The dimensions between the two ears (D7) measured the distance between the midpoint of the two ears. Ear area was obtained from the half of the height of front head. The margining box of each ear was made from the outermost side of the earlobe. The ears' midpoint was obtained from half of the height of ear margin box and 3/4 of half of the width to the right. The identified midpoints on both ears were then connected to generate the D7 dimension. Dimensions between two eye pupils (D10) identified the distance between the left eye pupil point to the right eye pupil point. Head was horizontally divided into two parts that separated between two eyes. The head was then divided again by $1 / 3$ of the face height and a half between $1 / 3$ and $2 / 3$ of the head height and $2 / 3$ of the midpoint of the head image width to the left and to the right to obtain the eye area. The determination of the points of right and left eye pupil was administered with same treatment. Each end of one eye was identified by looking at the darker colour intensity from surrounding skin tone. The tip of eye point will form a margining box of eye feature. Location of eye pupils was obtained from midpoint of that eye feature margining box. Then, a line was drawn from midpoint obtained from each eye to obtain the measurement of D10 dimension. Mouth width dimension (D4) measured the mouth distance in a normal expression. Mouth area was determined from division of the head of 2/3 of face height and 5/6 of head height as well as $1 / 3$ from the half width of head image to the left and right so that it formed a mouth feature margining box. The left and right ends of the mouth were identified by looking at the darker colour intensity. Dimension of the eye to the top of the head (D8) was calculated from one of eye pupil points to the top of the head. Dimension of the mouth to the top of the head (D13) was obtained from one end of the mouth to the top of the head.

Dimensions of the chin to the top of the head (D4) and the nose to the back of the head (D12) on the side head were obtained from the height and the width of head image. Nose dimension to the top of the head (D11) was obtained from the outermost point of the nose to the top of the head. The chin maximum diameter dimension (D3) was calculated from chin point to the top of the head diagonally. Head length dimension (D1) measured the distance from point between eyebrows and hairline to the furthest point on the back of the head. Dimension of the eye to the back of the head (D9) was obtained from eye point to the outermost point of back of the head sought in the eye area, which is 3/7 of head height. Dimension of ear to the top of the head (D5) and ear to the back of the head required midpoint of the ears from the side of the head first. Ear midpoint was obtained from 3 sides of ear margining box. i.e. upper ear side, lower ear side, and right ear side. Upper side of the ears was seen from pixel colour intensity with a more dominant brighter colour. The search for the position of the coordinate point on the upper side of the ear was started from $3 / 4$ to $2 / 5$ of side head heights and 3/4 to $2 / 5$ of side head widths. The searching technique used on the upper side of side ear was by saving coordinate point values of $x$ and $y$ with bright pixel colour value horizontally to the 
left or in a row to the left, then looking for pixel point on the next row vertically one level up into one array. The position of the upper side of the ear was obtained by looking at the position of the smallest $y$ point value in the array. The lower side of the ear was seen from the value of darker colour pixel intensity. The search of point coordinate position on the underside of the ear was started from areas of $2 / 5$ to $4 / 5$ of side head height and $2 / 5$ to $3 / 5$ of side head width. The searching technique for lower side of side ear was by searching one $x$ and $y$ coordinate with a value of darker pixel colour horizontally to the right or in a row to the right. If a dark pixel had been found in a row then the searching continued to the next row by vertically going down one level and being saved into the array. Underside position of side ear was obtained by looking at the value of the largest $y$ point in the array. The right position of the side ear was obtained with the same steps as the searching of upper side position of side ear. The right-side position of side ear was obtained from looking at the largest value of $x$ point in the array that already contained pixel position with brighter coloured pixel. After all of positions of these three ear sides are obtained, ear midpoint could be produced from a half of $y$ position between upper side and lower side of side ear. The position of $x$ point of side ear was obtained by finding the position of the largest $x$ point in the array with a darker pixel colour value from the right side of side ear, then calculating $1 / 2$ of the distance between the position of right side of side ear and position of $x$ point with a darker pixel that had been searched before. The position of dark coloured $x$ point on the side of the ear then shifted to the left $1 / 2$ of the distance between right side of side ear with its $x$-point position. The obtained midpoint was then used in D5 dimension by connecting the top of the head point and D6 dimension by connecting the ear midpoint to the outermost point of the back of the head.

\section{G. Calculation of Distance Dimensions}

The distance between one pixel to another pixel in the image can be found by using the Euclidean formula [12]. The Euclidean equation between $\left(i_{1}, j_{1}\right)$ pixel and $\left(i_{2}, j_{2}\right)$ pixel are

$$
d_{\text {Euclidean }}=\sqrt{\left(i_{1}-i_{2}\right)^{2}+\left(j_{1}-j_{2}\right)^{2}}
$$

The produced dimensional distance in pixel unit was then converted into centimetre. Value of one pixel per centimetre was obtained based on the head dimension (D4) in the distance between the head object and the fixed IP Camera. The value was then used in the calculation of front and side head dimensions.

$$
x=\frac{d^{\prime}}{d}
$$

with $x$ as a value of one pixel in centimetre, and $d$ as the D4 head dimension distance in pixel, and $d$ as the value of D4 head dimension with manual measurement using a calliper. The obtained $x$ value was then multiplied by the distance of head dimension in pixel unit $\left(d^{\prime}\right)$ to get the value of head dimension measurement in centimetre unit.

\section{H. Paired Sample T-Test}

Paired Sample T-Test method was used to compare between to interconnected samples, with one sample was given a specific treatment and then compared to samples before the treatment [13]. Paired sample t-test uses a hypothetical approach consisting of $\mathrm{HO}$ and $\mathrm{H} 1$. $\mathrm{H} 0$ is accepted when the two variable values are identical, while H0 is rejected or $\mathrm{H} 1$ is accepted when the two values are different. Determination of the hypothesis is based on the value of table $t$ and calculated $t$ if the value of calculated $t$ is smaller than table $t$ value. The value of table $t$ is obtained from the $t$ distribution table based on the number of samples used and the significance value $(\alpha)$. The calculated $t$ value was obtained using (4).

$$
|t|=\frac{\left(X_{1}-X_{2}\right)-0}{S d / \sqrt{n}}
$$

with $X_{1}$ and $X_{2}$ are the average of each variable, $S d$ is the standard deviation, and $n$ is the number of sample data. Standard deviation can be calculated using (5).

$$
S d=\sqrt{\frac{1}{(n-1)}\left\{\sum D^{2}-\frac{\left(\sum D\right)^{2}}{n}\right\}}
$$

where $n$ is the number of data and $D$ is the difference between the two variables.

Steps of paired Sample T-Test method consists of the following things.

1. Step 1

Define hypothesis, i.e. $\mathrm{H} 0$ and $\mathrm{H} 1$.

- $\mathrm{H} 0$ is a hypothesis stating that the value of system measurement dimension is identical with manual measurement.

- $\mathrm{H} 1$ is a hypothesis stating that the value of system measurement dimension is different from manual measurement.

2. Step 2

Determine the value of table $t$.

- The value of table $t$ was 2.045 based on the significance level of $5 \%$ and the number of samples was 30

3. Step 3

Calculate the standard deviation.

- Find the difference value of each data on two variables. i.e. manual measurement value and system measurement value.

- Calculate the square value of the difference obtained for each data.

- Calculate the standard deviation value using (5).

4. Step 4

Look for the value of calculated $t$ using (4).

5. Step 5

Determine the taken hypothesis based on the calculated $t$ value. 


\section{RESULTS AND DISCUSSION}

\section{A. Interface Implementation}

The system was built using the PHP programming language and MySQL database. The system consisted of three main pages, i.e. the home page, head image retrieval page, and head dimension data measurement result page.

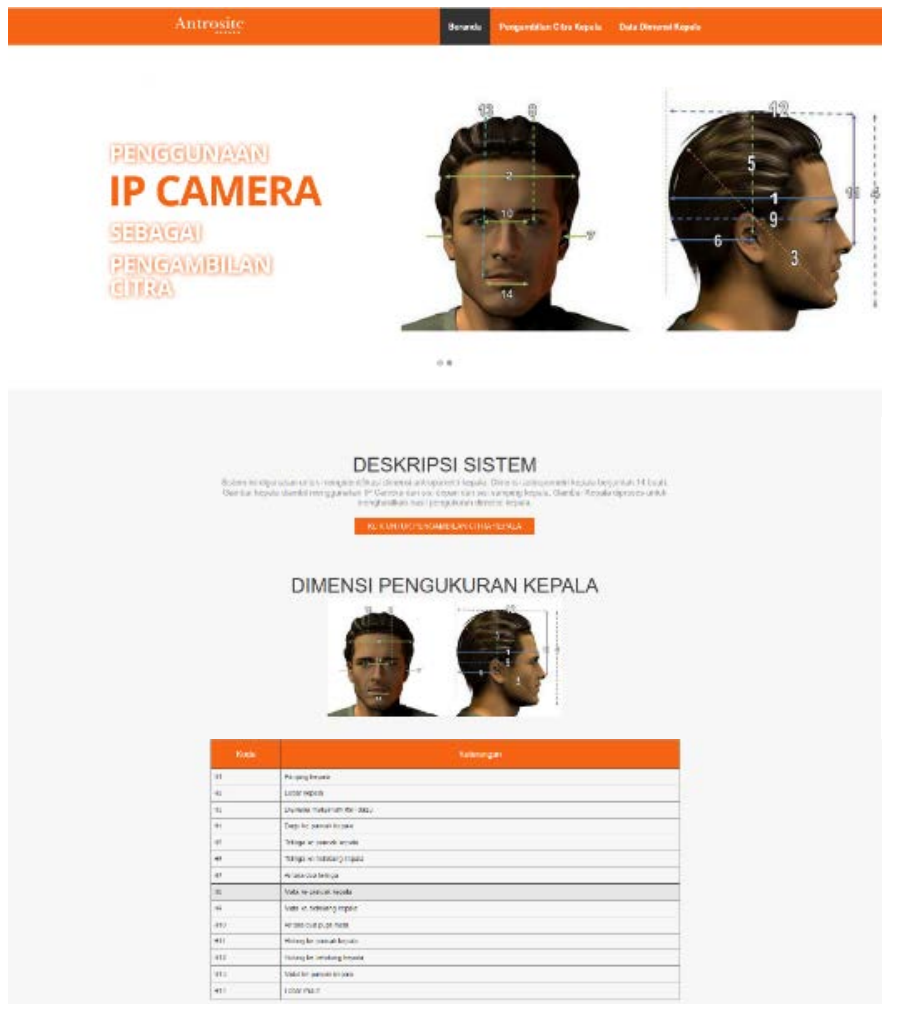

Fig. 5 Interface of system home page.

Fig. 5 is the home page in the system. This page contains a description of the initial system and explanations of the measured human head dimensions.

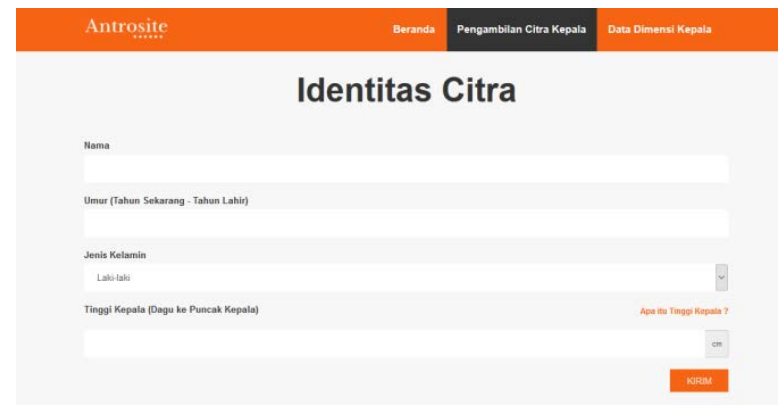

Fig. 6 Interface of image identity page.

Fig. 6 is the interface display of image identity page. Before the head image is taken, there are image identity details that must be completed i.e. name, age, gender and head height. This head height is used for conversion process of pixel value into centimetre.

Fig. 7 is the head image capture page. This page contains the view of IP Camera which is divided into two, IP Camera view for capturing front head image and IP Camera view for capturing side image. The head image capture started from front head first and then continued with capturing side head image.

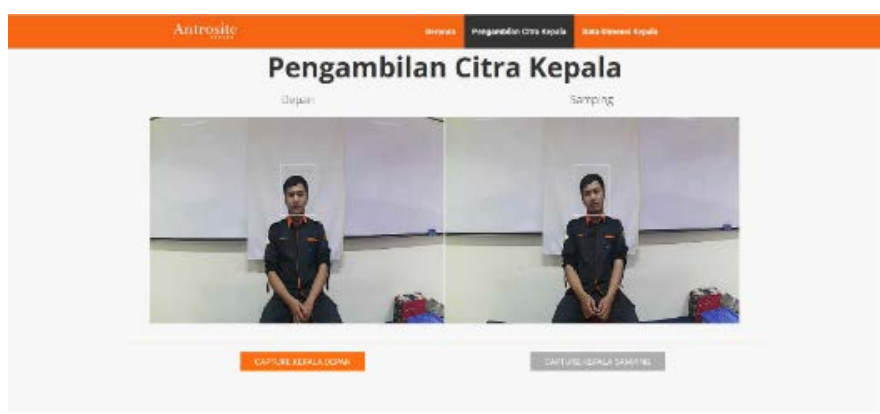

Fig. 7 Interface of head image capture page.

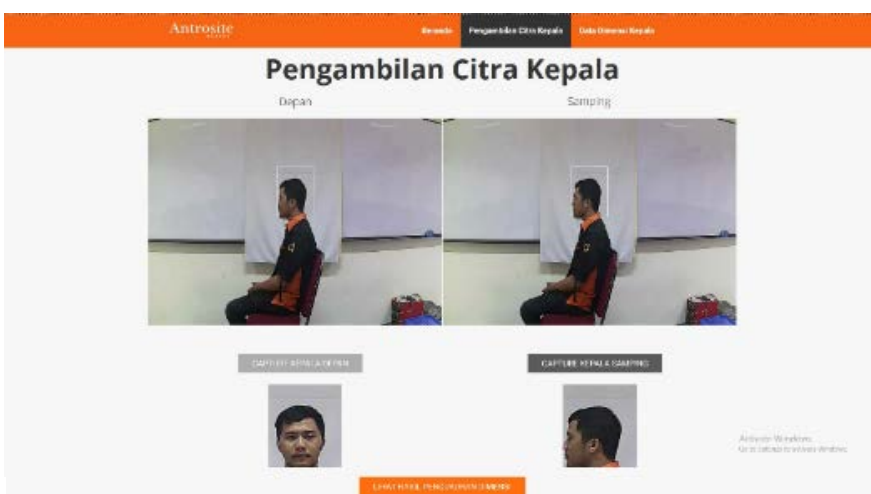

Fig. 8 Interface of head image capture page.

Fig. 8 is the head image capture page after capturing the front and side head images. After the head image was taken, the View Dimension Measurement Result button was pressed to see the system measurement results.

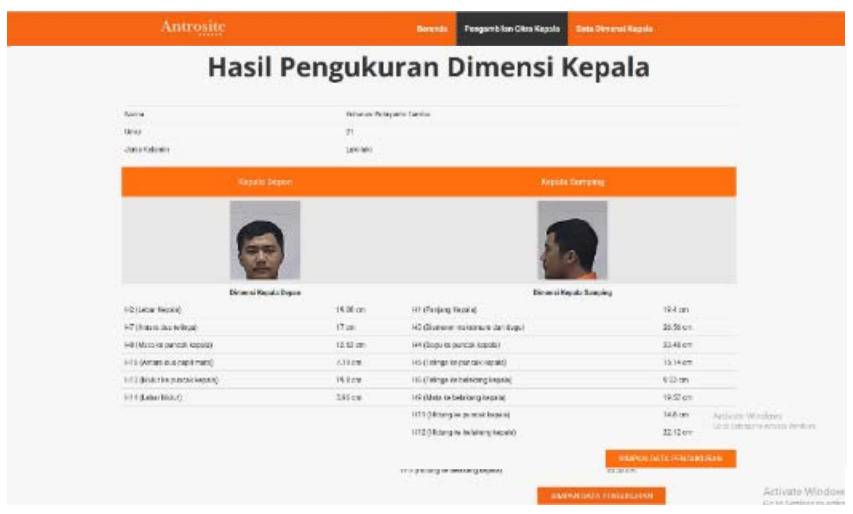

Fig. 9 Interface of head dimension measurement result.

Fig. 9 is the display of the head dimension measurement result after taking the front and side head images. This page contains information about the image identity including the name, age, gender as well as the result of head dimension measurement. The measurement result can be saved by pressing the 'Save Measurement Data into Database' button.

Fig. 10 is the display of head dimension data page containing information about all head dimension data that has been done before. That dimension data is saved in the database. 


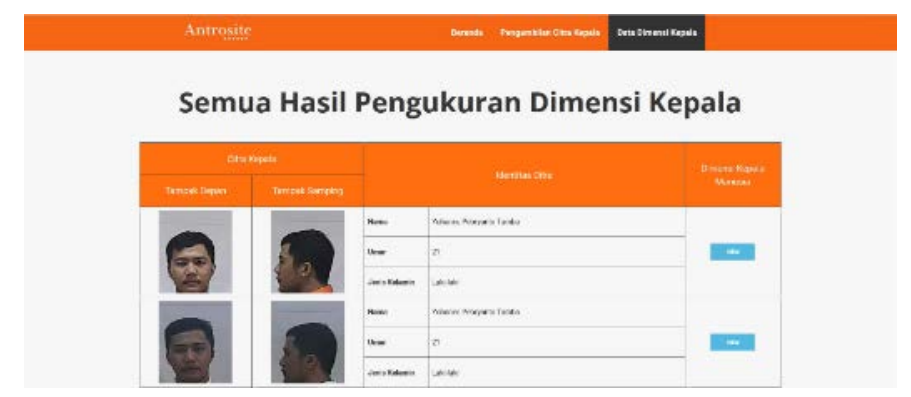

Fig. 10 Interface of head dimension data page.

\section{B. Human Head Image Capture}

Objects in this research were front and side parts of human head which images were taken with IP Camera with the distance between head object and the IP Camera of $206 \mathrm{~cm}$. With this distance, the IP Camera could take pictures of all front part and sides of the head. Background cloth was placed at the back of head object as far as $57 \mathrm{~cm}$. Distance between object and the background was arranged so that the result did not make a silhouette. IP Camera was placed on a tripod as a support or a cantilever so that the resulting image remains aligned or not slanted. Object would adjust head position to fit the set IP Camera capture area. Images of a human head that had been positioned on the IP Camera capture area were taken and saved into hard drive. Illustration of human head image retrieval is shown on the Fig. 11.

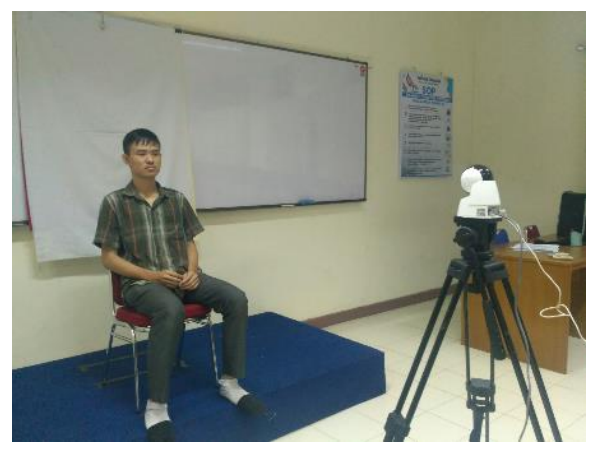

Fig. 11 Human head image capture.

\section{Head Image Conversion to Grayscale}

The human head image taken from the IP Camera is still in the RGB colour space. The image needs to be converted into the grayscale image needed to simplify the feature extraction process. The result of human head image conversion into grayscale is shown on Fig. 12.

The use of white background was done to ease the feature extraction process in measuring the dimension of anthropometry measurement of the front and sides of the human head. White background colour will distinguish head object with background so that the system can identify the head object.

\section{Result of Comparison of Manual and System Measurement}

After feature extraction process was done on the head image, then the distance dimension calculation was conducted with (2) and then being converted from pixel unit into centimetre unit to obtain the result of head dimensions measurement.

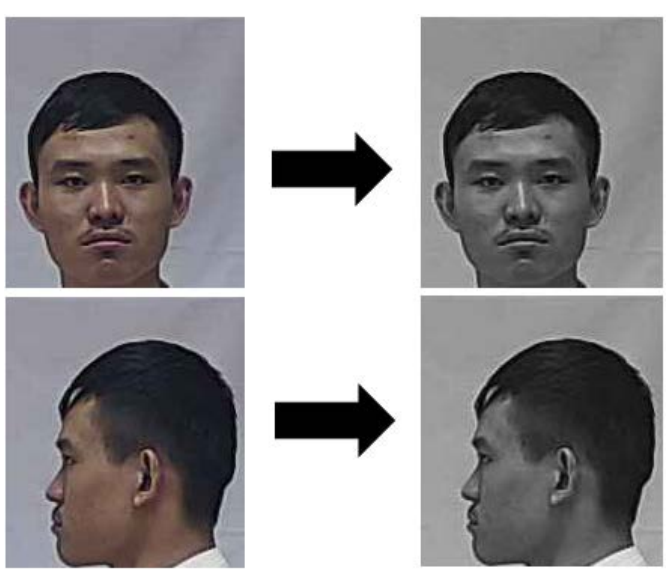

Fig. 12 Conversion of RGB image to grayscale.

The result of conducted measurement by the system was then being compared with the result of manual measurement using a calliper. This comparison was carried out to see the result of system measurement, if it had the same result or not with manual measurement. Each of manual and system measurement has thirty data for each head dimension. The average and difference in the average of the manual and system measurement of each head dimension results were calculated.

TABLE II

AVERAge of MANUAL AND SySTEM MEASUREMENTS COMPARISON

\begin{tabular}{|c|c|c|c|}
\hline $\begin{array}{c}\text { Head } \\
\text { Dimension }\end{array}$ & $\begin{array}{c}\text { Average } \\
\text { Manual } \\
\text { Measurement } \\
\text { (cm) }\end{array}$ & $\begin{array}{c}\text { Average System } \\
\text { Measurement } \\
\text { (cm) }\end{array}$ & $\begin{array}{c}\text { Difference of } \\
\text { Manual and } \\
\text { System } \\
\text { Measurement } \\
\text { (cm) }\end{array}$ \\
\hline D1 & 17.972 & 17.874 & 0.098 \\
\hline D2 & 16.353 & 16.403 & 0.050 \\
\hline D3 & 25.766 & 24.263 & 1.504 \\
\hline D4 & 21.817 & 21.817 & 0 \\
\hline D5 & 13.465 & 14.232 & 0.767 \\
\hline D6 & 8.7470 & 9.0810 & 0.334 \\
\hline D7 & 15.484 & 15.146 & 0.338 \\
\hline D8 & 11.148 & 11.069 & 0.079 \\
\hline D9 & 16.847 & 17.716 & 0.869 \\
\hline D10 & 6.4100 & 6.5210 & 0.112 \\
\hline D11 & 13.972 & 14.501 & 0.529 \\
\hline D12 & 19.955 & 20.186 & 0.231 \\
\hline D13 & 17.565 & 17.552 & 0.013 \\
\hline D14 & 5.0340 & 4.9700 & 0.064 \\
\hline
\end{tabular}

Based on the comparison of average manual and system measurements on Table II, it is known that the system measurement result is not the same as the manual measurement result. It is visible from the difference between the value of average manual measurement and average system measurement. Average value of manual and system measurements on D4 dimension (chin to the top of the head) are the same because the D4 dimension value was used as 
initial input for dimensional distance calculation process, i.e. conversion of head dimension measurement from pixel into centimetre.

\section{E. Head Distance Testing with IP Camera}

The distance change of the IP Camera with head object can affect the human head dimension measurement. This distance test was administered to obtain the best distance between head object with IP Camera by looking at the smallest average value of the difference between manual and system measurements. The tested distances were distances with a value of $150 \mathrm{~cm}, 175 \mathrm{~cm}, 200 \mathrm{~cm}, 225 \mathrm{~cm}, 250 \mathrm{~cm}$, and 275 $\mathrm{cm}$.

TABLE III

HeAd Distance Testing With IP CAMERA

\begin{tabular}{|c|c|c|}
\hline Distances & $\begin{array}{c}\text { Total Error } \\
\text { Difference } \\
\text { (cm) }\end{array}$ & $\begin{array}{c}\text { Average } \\
\text { Difference Error } \\
\text { (cm) }\end{array}$ \\
\hline $150 \mathrm{~cm}$ & Undetectable & Undetectable \\
\hline $175 \mathrm{~cm}$ & 15.520 & 1.109 \\
\hline $\mathbf{2 0 0} \mathbf{~ c m}$ & $\mathbf{1 1 . 5 8 7}$ & $\mathbf{0 . 8 2 8}$ \\
\hline $225 \mathrm{~cm}$ & 12.085 & 0.863 \\
\hline $250 \mathrm{~cm}$ & 13.843 & 0.989 \\
\hline $275 \mathrm{~cm}$ & 12.665 & 0.905 \\
\hline
\end{tabular}

Based on the results of distance testing in Table III, the best distance between the head object and the IP Camera in taking the head image is $200 \mathrm{~cm}$ with the smallest average error difference value. At a distance of $150 \mathrm{~cm}$, the test results are said to be undetectable because the obtained head objects look larger and do not cover the head thoroughly or there is a part of the head which is cut off. The distances of $175 \mathrm{~cm}, 225 \mathrm{~cm}$, $250 \mathrm{~cm}, 275 \mathrm{~cm}$ had resulted a larger average difference error than average difference error at a distance of $200 \mathrm{~cm}$, i.e. 0.828 .

\section{F. Hypothesis Determination with Paired Sample T-Test}

The dimension value obtained from the system was being compared with manual measurement with a calliper. This measurements comparison used Paired Sample T-Test with thirty samples for each manual measurements and sample data measurement system for each head dimension.

TABLE IV

RESUlt OF PAIRED SAMPLE T-TEST

\begin{tabular}{|c|c|c|}
\hline Head dimension & Calculated $\boldsymbol{t}$ & $\begin{array}{c}\text { Hypothesis } \\
\text { Result }\end{array}$ \\
\hline D3 & 5.158 & Accept H1 \\
\hline D5 & 5.133 & Accept H1 \\
\hline D9 & 3.096 & Accept H1 \\
\hline D11 & 2.568 & Accept H1 \\
\hline
\end{tabular}

According to hypothesis results from paired Sample T-Test on Table IV, there are four head dimensions that accept H1 hypothesis with the calculated $t$ value more than 2.045 . Calculated $t$ value is bigger than 2.045 indicates that comparison result between system measurement and manual measurement are different. From the result of paired sample $\mathrm{T}$-Test, it can be stated that the other ten head dimensions are identical because the calculated $t$ value is smaller than 2.045 . It states that there is no difference between manual measurement using a calliper with the measurement generated by the system.

There several factors influencing the results of system measurement. Darker skin colour affects the process of head dimensions measurement, so that there might be some errors occur in the taken measurements. Other factor affecting the system accuracy is the hair. Hair which is not so thick or long can also affect the result of head dimension measurement. Hair on front part of the head did not cover forehead when the image was taken, and hair on side of the head did not cover the ears. Head condition when taking the image did not use additional accessories such as hat, veil, and other head coverings that covered the head.

\section{CONCLUSION}

Based on the obtained result it can be concluded that anthropometric dimensions of human head measurement can be successfully identified based on the pixel measurement in the image. The best distance between head object and the IP Camera based on the tests administered in taking human head image is $200 \mathrm{~cm}$. Measurement process administered by the system is faster than the manual measurement using a calliper. The head dimension measurement administered in this research is more efficient than previous research because the system that has been built can directly process the human head images without any image data transferring process from camera into the system.

There is still a H1 hypotheses in the testing result of paired Sample T-Test on the human head anthropometry dimension, i.e. the manual measurement is different with system measurement. This is because of the facial skin colour of a darker human head during the image taking and also the hair length and thickness had made the system measurement being inaccurate.

\section{REFERENCES}

[1] I. Santoso, Interaksi Manusia dan Komputer, 2nd ed. Yogyakarta, Indonesia: ANDI, 2011.

[2] S. Wignjosoebroto, "Evaluasi Ergonomis dalam Proses Perancangan Produk," presented as Keynote Speech at Seminar Nasional Ergonomi, Surabaya, 2000, pp. 1-7.

[3] C.N. Rosyidi, $\mathrm{N}$ Riyanti, and I. Iftadi, "Head and Facial Anthropometry for Determining the Critical Glasses Frame Dimensions," Journal of Engineering Science and Technology, Vol. 11, No. 11, pp. 1620-1628, 2016.

[4] Z. Zhuang and B. Bradtmiller, "Head-and-Face Anthropometric Survey of U.S. Respirator Users," Journal of Occupational and Enviromental Hygiene, Vol. 2, pp. 567-576, 2005.

[5] B. Brennan, S. Wignjosoebroto, and A. Sudiarno, "Perancangan Sistem Pengukuran Antropometri Kepala Menggunakan Teknologi Image Processing dengan Metode Ekstraksi Fitur Wajah," Thesis, Institut Teknologi Sepuluh Nopember, Surabaya, Indonesia, 2009.

[6] (2013) Pentingnya Antropometri, [Online], http://antropometriindonesia.org/index.php/detail/sub/2/7/4/pentingnya _antropometri, accessed: 14 May 2017.

[7] R. Wiryadinata, U. Istiyah, R. Fahrizal, Priswanto, and S. Wardoyo, "Sistem Presensi Menggunakan Algoritme Eigenface dengan Deteksi Aksesoris dan Ekspresi Wajah,” Jurnal Nasional Teknik Elektro dan 
Teknologi Informasi (JNTETI), Vol. 6, No. 2, pp. 222-229, 2017.

[8] S. Putra, I. Muslim, and M.I. Zul, "Identifikasi Aktifitas Manusia di dalam Ruangan Menggunakan IP Camera dengan Metode Template Matching dan Algoritma Klasifikasi," 4th Applied Business and Engineering Conference, 2016, pp. 1-5.

[9] M.I. Zul, "Feature Extraction for Hand Shape Recognition by Using IP Camera," Proc. of Regional Conference on Computer and Information Engineering, 2014, pp. 112-115.

[10] N. Hayatin, "Pengelompokan Usia Berdasarkan Citra Wajah Menggunakan Algoritma Neural Network dengan Fitur Face Anthropometry dan dalam Kerutan,” Teknologi, Vol. 6, pp. 178-184, 2016.
[11] A. Kadir and A. Susanto, Teori dan Aplikasi Pengolahan Citra, Yogyakarta, Indonesia: ANDI, 2013.

[12] R. Munir, Pengolahan Citra Digital dengan Pendekatan Algoritmik, Bandung, Indonesia: Informatika, 2004.

[13] S. Santoso, Buku Latihan SPSS Statistik Parametrik, Jakarta, Indonesia: PT Elex Media Komputindo, 2000. 